\title{
Two-Stage Chaos Optimization Search Application in Maximum Power Point Tracking of PV Array
}

\author{
Lihua Wang, ${ }^{1,2}$ Xueye Wei, ${ }^{1}$ Tianlong Zhu, ${ }^{1}$ and Junhong Zhang' \\ ${ }^{1}$ School of Electronic and Information Engineering, Beijing Jiaotong University, Beijing 100044, China \\ ${ }^{2}$ School of Electronic Communication \& Physics, Shandong University of Science \& Technology, Qingdao 266590, China \\ Correspondence should be addressed to Lihua Wang; wanglihua7141@163.com
}

Received 11 April 2014; Revised 25 November 2014; Accepted 25 November 2014; Published 11 December 2014

Academic Editor: Gerhard-Wilhelm Weber

Copyright (c) 2014 Lihua Wang et al. This is an open access article distributed under the Creative Commons Attribution License, which permits unrestricted use, distribution, and reproduction in any medium, provided the original work is properly cited.

\begin{abstract}
In order to deliver the maximum available power to the load under the condition of varying solar irradiation and environment temperature, maximum power point tracking (MPPT) technologies have been used widely in PV systems. Among all the MPPT schemes, the chaos method is one of the hot topics in recent years. In this paper, a novel two-stage chaos optimization method is presented which can make search faster and more effective. In the process of proposed chaos search, the improved logistic mapping with the better ergodic is used as the first carrier process. After finding the current optimal solution in a certain guarantee, the power function carrier as the secondary carrier process is used to reduce the search space of optimized variables and eventually find the maximum power point. Comparing with the traditional chaos search method, the proposed method can track the change quickly and accurately and also has better optimization results. The proposed method provides a new efficient way to track the maximum power point of $\mathrm{PV}$ array.
\end{abstract}

\section{Introduction}

It is well known that the output power of a photovoltaic (PV) cell or panel varies with the change of external environment and load; the output power can be maximized by operating at a specific point on its exponential voltage-current characteristic curve. Under the same external environment such as irradiation and temperature, $\mathrm{PV}$ system requires the $\mathrm{PV}$ cell to produce more power. In order to bring the efficiency of PV device into full play, maximum power point tracking (MPPT) techniques [1-3] are commonly used in PV system. The function of MPPT is to detect the real-time output of PV array and make the PV system run well under the optimum work state. However, the output characteristic of PV cell is complex and nonlinear. It is difficult to determine its mathematical model accurately. How to design the highperformance systems for extracting maximum energy from photovoltaic arrays has become a focus and hotspot in the research of PV system.

The characteristics of PV arrays are low conversion efficiency, nonlinear, and dependent on irradiation and environment temperature. All these characteristics showed that
MPPT control is a complex and comprehensive problem. Over the past decades, many papers have developed a variety of MPPT algorithms for PV arrays, including the voltage feedback method [4], perturbation and observation ( $\mathrm{P} \& \mathrm{O})$ method [5, 6], conductance increment method [7], optimal gradient method [8], intermittent control scanning method [9], and so forth. In recent years, with the development of the theory of intelligent control, PID/fuzzy control methods [10-12], evolutionary algorithm method [13], artificial neural network method [14], and so on are also applied in the area of MPPT. Every method has its own advantage and disadvantage. In this paper, in order to improve the performance of traditional chaos search, a new two-stage chaos optimization algorithm is proposed.

\section{PV Cell Model and Characteristics}

2.1. Basic Model of PV Cells. The equivalent circuit of the ideal PV cell [15] is shown in Figure 1.

PV cells are usually series or parallel connected to reach the desired voltage and power. Assuming that a PV array 


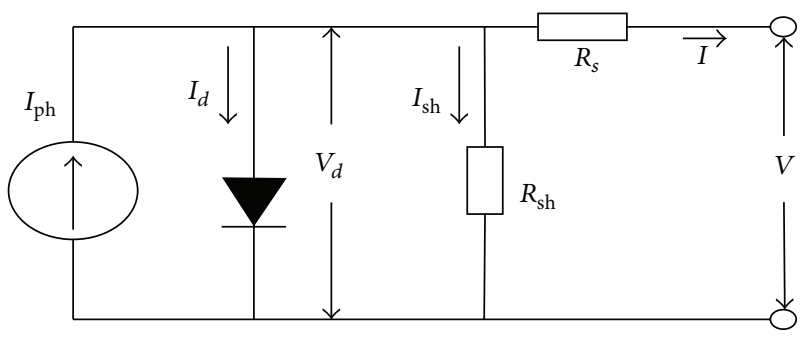

Figure 1: Equivalent circuit of PV cell.

consists of $N_{s}$ PV cells connected in series, $N_{p}$ PV cells connected in parallel, and neglecting the influence of the shunt resistance $R_{\mathrm{sh}}$, the $V_{\mathrm{PV}}-I_{\mathrm{PV}}$ characteristic equation is given as follows [15-18]:

$$
\begin{aligned}
I_{\mathrm{PV}}= & N_{p} I_{\mathrm{ph}} \\
& -N_{p} I_{\mathrm{sat}}\left(\exp \left(\frac{q\left(V_{\mathrm{PV}} / N_{S}+I_{\mathrm{PV}} R_{s} / N_{p}\right)}{n k T}\right)-1\right),
\end{aligned}
$$

where $n$ is the diode ideality factor, $k$ is Boltzmann's constant, $T$ is the absolute temperature, $q$ is the electron charge, $I_{\mathrm{ph}}$ is the light-generated current, $I_{\text {sat }}$ is the reverse saturation current of the $p$ - $n$ diodes, $R_{s}$ is the series resistance of the PV module, and their values can be referenced in $[15,17]$.

The PV array power can be described as follows:

$$
\begin{aligned}
P_{\mathrm{PV}}= & N_{p} I_{\mathrm{ph}} V_{\mathrm{PV}} \\
& -N_{p} I_{\mathrm{sat}} V_{\mathrm{PV}}\left(\exp \left(\frac{q\left(V_{\mathrm{PV}} / N_{S}+I_{\mathrm{PV}} R_{s} / N_{p}\right)}{n k T}\right)-1\right) .
\end{aligned}
$$

2.2. Output Characteristic of PV Cell. From (1) and (2) we can see that the output characteristics of PV array are highly nonlinear, which are effected by the change of internal parameters and external environmental factors. However, when the irradiation and temperature are certain, the $P_{\mathrm{PV}^{-}}$ $V_{\mathrm{PV}}$ and $I_{\mathrm{PV}}-V_{\mathrm{PV}}$ characteristics can be expressed; it indicates that the maximum power point (MPP) of PV array can also be extracted under certain irradiation and temperature. The purpose of MPPT is to search the optimal working state of $\mathrm{PV}$ array, that is, to seek the optimal operating point on the $P_{\mathrm{PV}}-V_{\mathrm{PV}}$ curves.

\section{Chaos Optimization Search Method}

Chaos is a universal complex nonlinear phenomenon which has many good properties such as ergodicity, regularity, and randomicity. The ergodicity and regularity mean a chaos motion can go nonrepeatedly through every state in a certain domain. The randomicity means that a chaos motion might be sensitive to the initial conditions. By using these properties, the chaos optimization method for solving complex problems was proposed [19-21], which is a stochastic search algorithm that differs from any of the existing evolutionary algorithms. The usual way to accomplish the algorithm is to produce chaos variables by single carrier at first. Secondly, transform the variables from chaos space into the solution space. Finally, try to find out the optimal solution with the chaos characteristics of randomness, ergodicity, and regularity.

The traditional chaos optimization algorithm, which usually uses single carrier, has poor search ability. It may take a long time for traditional chaos search to reach some special state [22]. That means that it cannot provide enough speed to track the MPP of PV system. In order to overcome the shortcomings of chaos optimization algorithm, some new approaches are proposed $[23,24]$. In this paper, a two-stage chaos optimization search method is first applied in the field of MPPT. The proposed method will improve the efficiency of chaos search and overcome the blindness of traditional chaos search.

3.1. Chaos Mapping and First Carrier. The chaos optimization search is achieved through the chaos variables. There are many methods to produce chaos variables, among them the logistic mapping method [25] is generally selected; the equation is expressed as follows:

$$
x_{n+1}=\mu x_{n}\left(1-x_{n}\right) \quad n=1,2,3, \ldots,
$$

where $\mu$ is a control parameter, it is easy to prove that, when $\mu=4$, (3) is completely in chaos condition [21]. $x_{n}$ is ergodic within $[0,1]$. The logistic mapping bifurcation diagram is shown in Figure 2(a). Take different initial values between 0 and 1 (except some fixed value such as $0,0.25,0.5,0.75$, and 1 ); we can get different chaos variables with different orbits by iteration. Go on iterating; any variable in the optimization space can be obtained, as shown in Figure 2(b).

In Figure 2, the chaos variables produced by the logistic mapping are ergodic, but the uneven distribution (denser on both ends and sparser in the centre) of orbital points will weaken its ergodicity.

In order to give full play to the ergodicity of chaos variables, the probability density of logistic mapping should be improved (namely, reducing the probability density on both ends, meanwhile, increasing the probability density in the centre). In this paper, a power function is adopted. The function can be written as follows:

$$
x_{n}^{j}= \begin{cases}x_{n}^{w}, & x_{n} \in[0, \gamma] ; \\ x_{n}^{v}, & x_{n} \in[\gamma, \lambda] ; \\ x_{n}^{r}, & x_{n} \in[\lambda, 1],\end{cases}
$$

where $0<\gamma<\lambda<1,0<w<1,0<v<1, r>1, x_{n}$ is the original chaos variables, and $x_{n}^{j}$ is the new chaos variables. If $x_{n} \in[0, \gamma], 0<w<1$, then $x_{n}^{j}>x_{n}$; it will make the points at the bottom move up; if $x_{n} \in[\lambda, 1], r>1$, then $x_{n}^{j}<x_{n}$; it will make the points at the top move down. The smaller the size of $w$ and the larger the size of $r$, the greater the size of moving distance. It is easy to prove that $x_{n}^{j} \in[0,1]$, and $x_{n}^{j}$ is still ergodic in the interval $[0,1]$. When $\gamma=0.7$, 


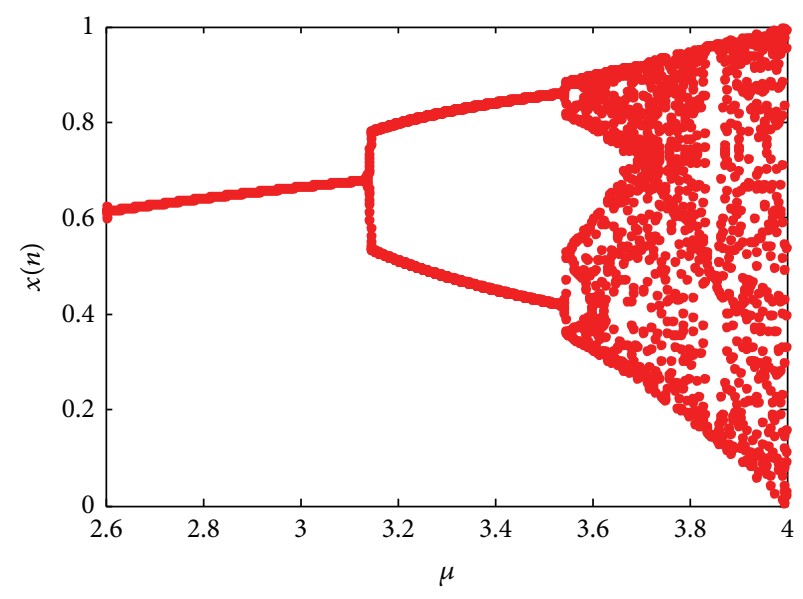

(a) Bifurcation diagram of the modified logistic mapping

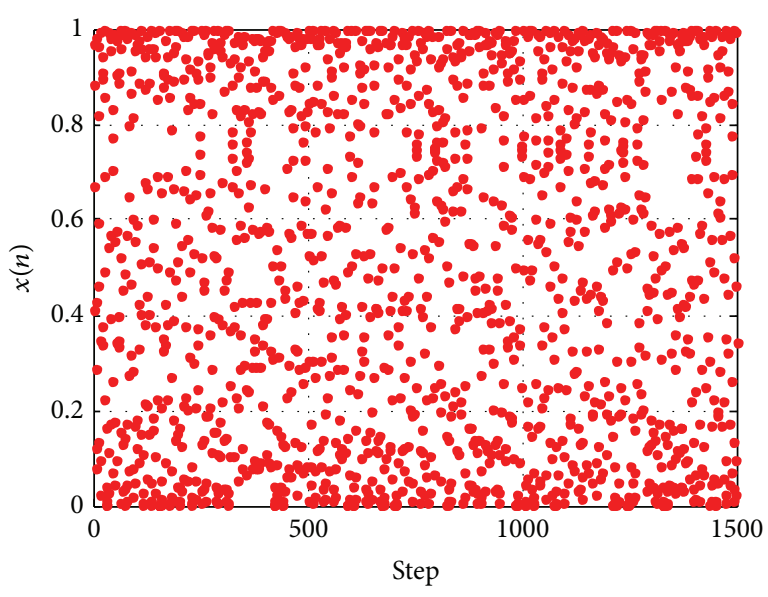

(b) Iterative sequence of logistic mapping

FIGURE 2: Bifurcation diagram and iterative sequence of logistic mapping.

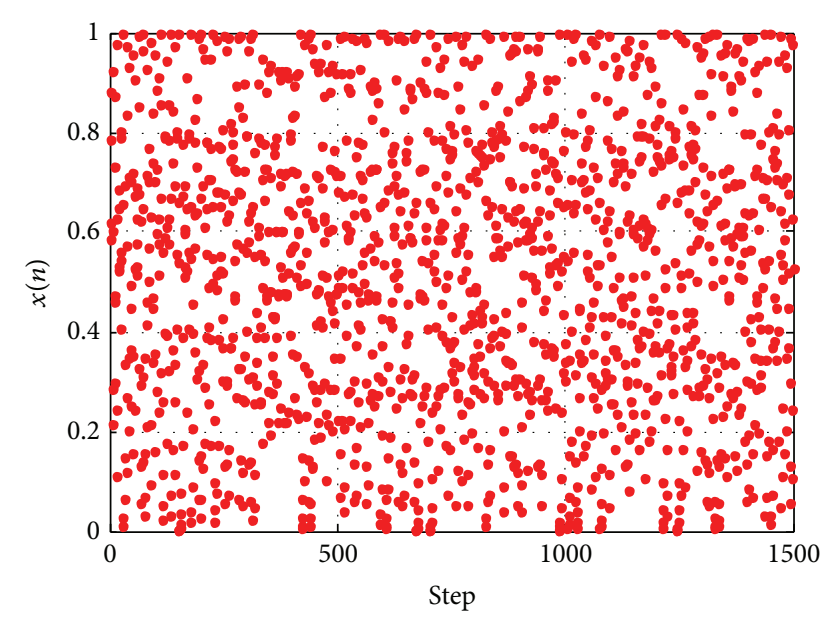

FIGURE 3: Iterative sequence of the modified logistic mapping.

$\lambda=0.9, w=0.4, v=0.6$, and $r=3.9$, the ergodicity of $x_{n}^{j}$ is depicted in Figure 3 . We can see that the probability density becomes more well-distributed: it is decreasing significantly than before near the ends and obviously increasing in the centre. The improved logistic mapping is used as the first carrier process of chaos optimization algorithm in this paper.

\subsection{Search Space Mapping and Reducing}

3.2.1. Search Space Mapping. The chaos variable $x_{n}^{j} \in[0,1]$, which is produced by the first carrier, must be transformed into the solution space (namely, the output voltage range of $\mathrm{PV}$ array); the transform equation is given as below:

$$
x_{n}^{\prime}=c_{l}+d_{l} x_{n}^{j}
$$

where $c_{l}$ and $d_{l}$ are the parameters whose initial values are related to $[a, b]$ and $a$ and $b$ are the boundary value of output

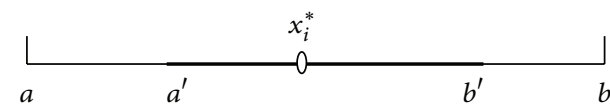

FIGURE 4: Diagram of reducing the search space.

voltage. The initial values of $c_{l}$ and $d_{l}$ can be described as follows:

$$
c_{l}=a ; \quad d_{l}=b-a
$$

3.2.2. Search Space Reducing. The diagram of reducing the search space is shown in Figure 4. The process is described as below: assuming $x_{i}^{*}$ is the current optimal solution, the distances $L_{x a}=x_{i}^{*}-a$ and $L_{x b}=b-x_{i}^{*}$ are not equal. In the next search, the new search space is $\left[a^{\prime}, b^{\prime}\right]$, the center is $x_{i}^{*}$, and the radius is $\min \left(L_{x a}, L_{x b}\right) / r_{1}$. From Figure 4 , we can see

$$
\begin{aligned}
& a^{\prime}=x_{i}^{*}-\frac{\min \left(\left|a-x_{i}^{*}\right|,\left|b-x_{i}^{*}\right|\right)}{r_{1}} \\
& b^{\prime}=x_{i}^{*}+\frac{\min \left(\left|a-x_{i}^{*}\right|,\left|b-x_{i}^{*}\right|\right)}{r_{1}},
\end{aligned}
$$

where $r_{1}$ is a constant, $r_{1} \geq 1$. According to (5), the new values of $c_{l}^{\prime}$ and $d_{l}^{\prime}$ can be written as follows:

$$
c_{l}^{\prime}=a^{\prime} ; \quad d_{l}^{\prime}=b^{\prime}-a^{\prime} .
$$

Then,

$$
\begin{gathered}
c_{l}^{\prime}=x_{i}^{*}-\frac{\min \left(\left|a-x_{i}^{*}\right|,\left|b-x_{i}^{*}\right|\right)}{r_{1}}, \\
d_{l}^{\prime}=2 \times\left(\frac{\min \left(\left|a-x_{i}^{*}\right|,\left|b-x_{i}^{*}\right|\right)}{r_{1}}\right) .
\end{gathered}
$$

Consider the following:

$$
a=c_{l} ; \quad b=c_{l}+d_{l} .
$$




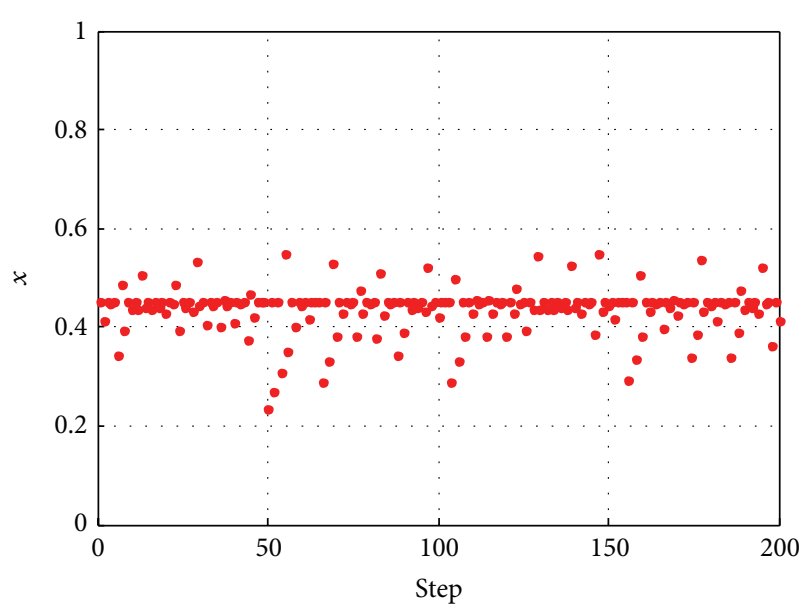

FIGURE 5: The ergodicity of $x_{n}^{\prime \prime}$.

The equation of search space reducing can be given by

$$
\begin{gathered}
c_{l}^{\prime}=x_{i}^{*}-\frac{\min \left(\left|c_{l}-x_{i}^{*}\right|,\left|d_{l}+c_{l}-x_{i}^{*}\right|\right)}{r_{1}}, \\
d_{l}^{\prime}=2 \times\left(\frac{\min \left(\left|c_{l}-x_{i}^{*}\right|,\left|d_{l}+c_{l}-x_{i}^{*}\right|\right)}{r_{1}}\right) .
\end{gathered}
$$

3.3. The Secondary Carrier. The secondary carrier of chaos optimization algorithm for refine search is as shown in

$$
x_{n}^{\prime \prime}= \begin{cases}x^{*} \times x_{1 t}^{\alpha} & \text { when } n \text { is odd } \\ x^{*}+\left(1-x^{*}\right) \times x_{2 t}^{\beta} & \text { when } n \text { is even }\end{cases}
$$

where $x^{*}$ is a given point (i.e., a current optimal solution), $x_{1 t}$ and $x_{2 t}$ are chaos variables produced by (3), respectively, $0<\alpha<1$, and $\beta>1$. From (12), it is easy to see that when $n$ is odd, $x_{n}^{\prime \prime} \in\left[0, x^{*}\right]$ is ergodic; when $n$ is even, $x_{n}^{\prime \prime} \in\left[x^{*}, 1\right]$ is also ergodic. Therefore, $x_{n}^{\prime \prime} \in[0,1]$ is ergodic in the area $[0,1]$.

If $\alpha$ is set to a small value and $\beta$ is set to a big one, then we can acquire the distribution of chaos sequence $x_{n}^{\prime \prime}$, as shown in Figure 5. The figure shows that $x_{n}^{\prime \prime}$ has higher density and better ergodicity near the given point of $x^{*}$.

3.4. Chaos Optimization Search Strategy for MPPT of PV Array. The output characteristic of PV array is highly nonlinear, as previously mentioned, and chaos optimization is mainly to solve the optimization problem for nonlinear multimodal function with boundary constraints. The question can be described as follows:

$$
f=f\left(x_{i}^{*}\right)=\max f\left(x_{i}\right) \quad x_{i} \in[a, b] \quad i=1,2,3, \ldots, N,
$$

where $x_{i}$ is the optimization variable; it is a vector that its dimension equals to the parameter number of optimization problem. In this paper, it means output voltage of PV array. $N$ is the number of optimization variable; $f\left(x_{i}\right)$ is the mathematical model for optimization problems; here, it means the output power of PV array. If the output power of PV array depends on the continuous objective function, $f\left(x_{i}^{*}\right)$ is the maximum output power of PV array, and $x_{i}^{*}$ is the output voltage of maximum power point.

The traditional chaos search is blindness; that is, it is difficult to determine the search times which are related to the complexity of objective function and the size of optimization space. So, it cannot guarantee the quality of search [26, 27]. In order to improve MPPT precision and speed in PV system, in this paper, the process of chaos optimization search was divided into two stages: the rough search based on the first carrier process and the refine search based on the secondary carrier. The proposed method is easy to realize and has high efficiency in search process.

In normal conditions, the proposed two-stage search algorithm can be described as follows.

Step 1 (initialization). Initialize $k=0, k^{\prime}=0, p^{*}=0$, $a=0, b=50, L_{1}=6, L_{2}=100, L_{3}=3, \alpha=0.5$, and $\beta=3$. $k$ and $k^{\prime}$ are iterative signs of chaos variables in first and secondary carrier, respectively, $k$ and $k^{\prime}=0,1,2, \ldots, n$. Put initial values which have very small differences into $x_{i}(0)$, $0<x_{i}(0)<1, i=0,1,2, \ldots, m$; then it can produce $m$ trajectories of different chaos variables. $p^{*}$ is the objective function; here, it is the maximum output power of PV array. $a$ and $b$ are the boundary value of the output voltage of PV array. $L_{1}$ is the number of iterations while $p^{*}$ keeping constant. $L_{2}$ is the number of rough or refine searches. $L_{3}$ is the number of global searches.

Step 2 (the first chaos optimization search (rough search)). Producing chaos variables $x_{i}(k)$ according to (3) and then putting $x_{i}(k)$ into $(4)$, new chaos variables $x_{i}^{j}(k)$ can be obtained easily. Then, map $x_{i}^{j}(k)$ to the optimal variables $x_{i}^{\prime}(k)$ (namely, the output voltage of PV array) according to (5).

Calculating $p(k)$, if $p(k)>p^{*}$, then $p^{*}=p(k), x_{i}^{*}=$ $x_{i}^{\prime}(k)$, else, abandon $x_{i}^{\prime}(k), k=k+1$. Loop until $p^{*}$ remain unchanged after $L_{1}$ times or the iterations $k$ is greater than $L_{2}$.

Step 3 (the 2nd chaos optimization search (refine search)). Producing chaos variables $x_{1 t}\left(k^{\prime}\right)$ and $x_{2 t}\left(k^{\prime}\right)$ according to (3) and substituting them into (14), then get a new chaos variables $x_{i}^{\prime \prime}\left(k^{\prime}\right)$, where $x_{i}^{*}$ is the current optimal solution from the first chaos optimization search.

Calculating $p\left(k^{\prime}\right)$, if $p\left(k^{\prime}\right)>p^{*}$, then $p^{*}=p\left(k^{\prime}\right), x_{i}^{*}=$ $x_{i}^{\prime \prime}\left(k^{\prime}\right)$, else, abandon $x_{i}^{\prime \prime}\left(k^{\prime}\right), k^{\prime}=k^{\prime}+1$. Loop until $p^{*}$ remain unchanged $L_{1}$ times or the iterations $k^{\prime}$ are greater than $L_{2}$.

Step 4 (reduce the search space and improve the convergence speed). Take the current optimal solution $x_{i}^{*}$ as the center, adjusting $c_{l}$ and $d_{l}$ to reconstruct the domain range of optimal variables, according to (11). Meanwhile, adjusting $\alpha$ and $\beta$ to speed up the convergence speed of the algorithm, according to

$$
\alpha=\frac{\alpha}{r_{2}}, \quad \beta=\beta \times r_{2},
$$

where $r_{2}$ is a constant, $r_{2} \geq 1$, and then return to Step 2 . 


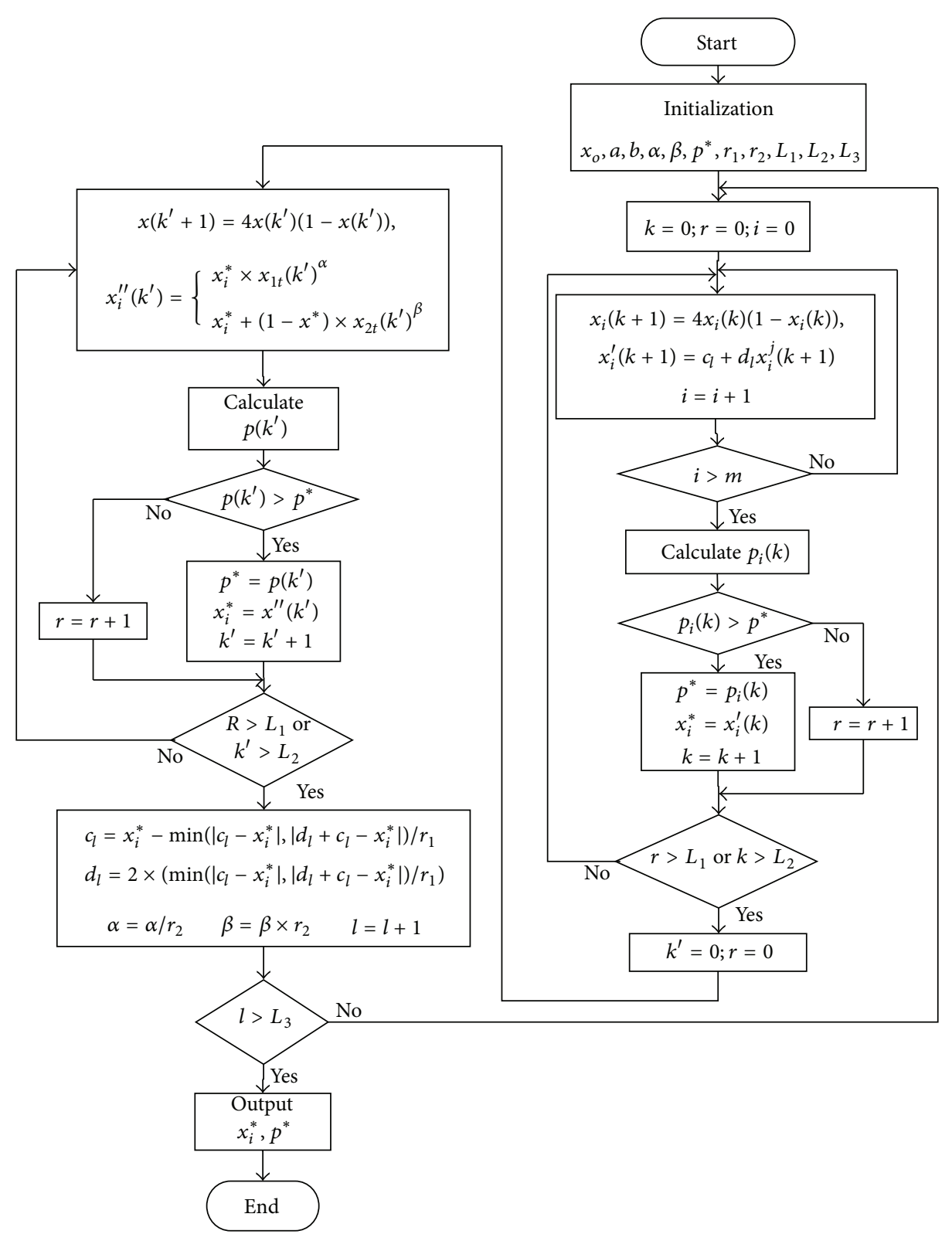

FIGURE 6: Block flow diagram of MPPT process.

Step 5 (output). As soon as the number of whole loop is greater than $L_{3}$, the whole loop terminates; output the maximum power $p^{*}$ and the optimal output voltage $x_{i}^{*}$.

In Figure 6, it is the block flow diagram of MPPT process (including partial shading condition).

\section{Simulation Experiment}

4.1. Tracking Simulation for Step Response. By comparing the proposed two-stage method to the traditional chaos search and perturbation and observation ( $\mathrm{P} \& \mathrm{O})$ search which are commonly used, we can get the step response tracking results as shown in Figure 7. According to the simulation results, the $\mathrm{P} \& \mathrm{O}$ search tracked rapidly; it took less than $0.02 \mathrm{~s}$ to reach the operating point, but it had inherent voltage ripple on the output of a PV system; the single carrier chaos search tracked steadily but slowly, more than 0.07 s to keep stable; the proposed method just needs about less than 0.03 s to reach the tracking object and make the system output steadily.

4.2. Simulation Model and Circuit Structure. According to the mathematical model of PV array as mentioned in Section 2, the simulation model of PV cell was built by MATLAB/Simulink, as shown in Figure 8. This paper takes the single-crystal silicon (whose type is JSM120W, made in JESENSOLAR) as the simulation prototype. Its parameters under standard test condition (STC: irradiation $1000 \mathrm{~W} / \mathrm{m}^{2}$, temperature $298 \mathrm{~K}$ ) are as below: open circuit voltage $U_{\mathrm{oc}}=$ $52.1 \mathrm{~V}$; MPP voltage $U_{\mathrm{mpp}}=44.9 \mathrm{~V}$; short circuit current $I_{\mathrm{sc}}=2.82 \mathrm{~A} ; \mathrm{MPP}$ current $I_{\mathrm{mp}}=2.589 \mathrm{~A}$; short circuit current variation coefficient with change of temperature 


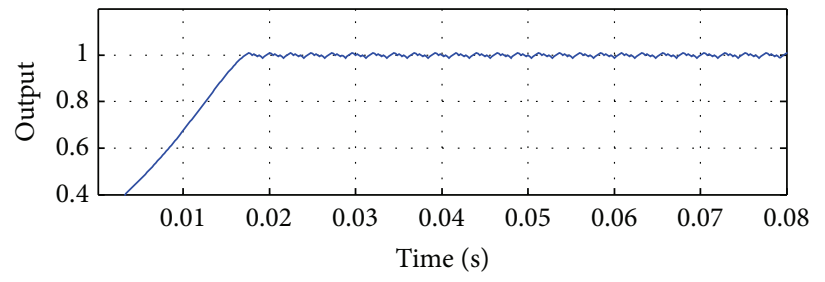

(a)

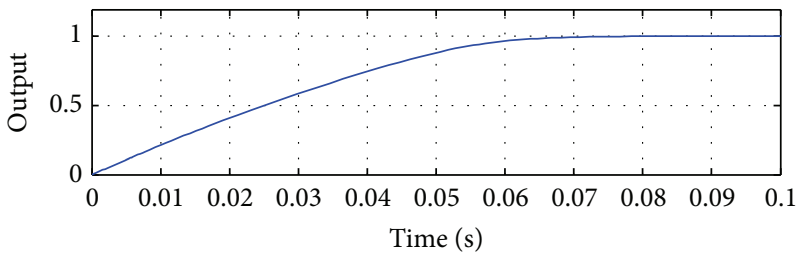

(b)

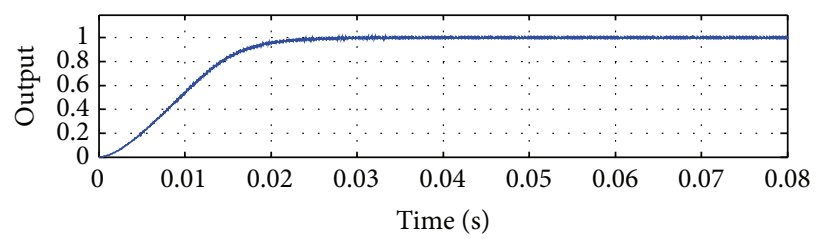

(c)

Figure 7: Tracking results of step response by three methods. (a) P\&O, (b) single chaos, and (c) two-stage chaos.

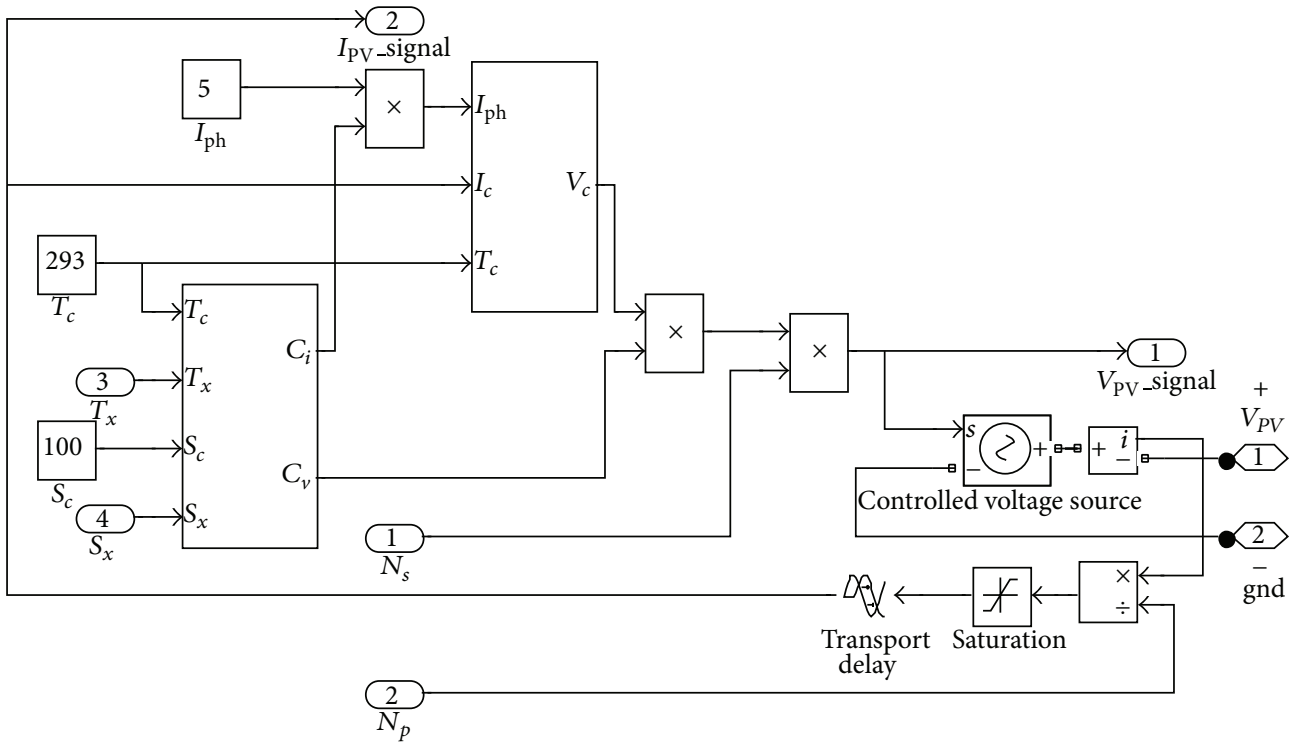

FIgURE 8: The simulation model of photovoltaic array.

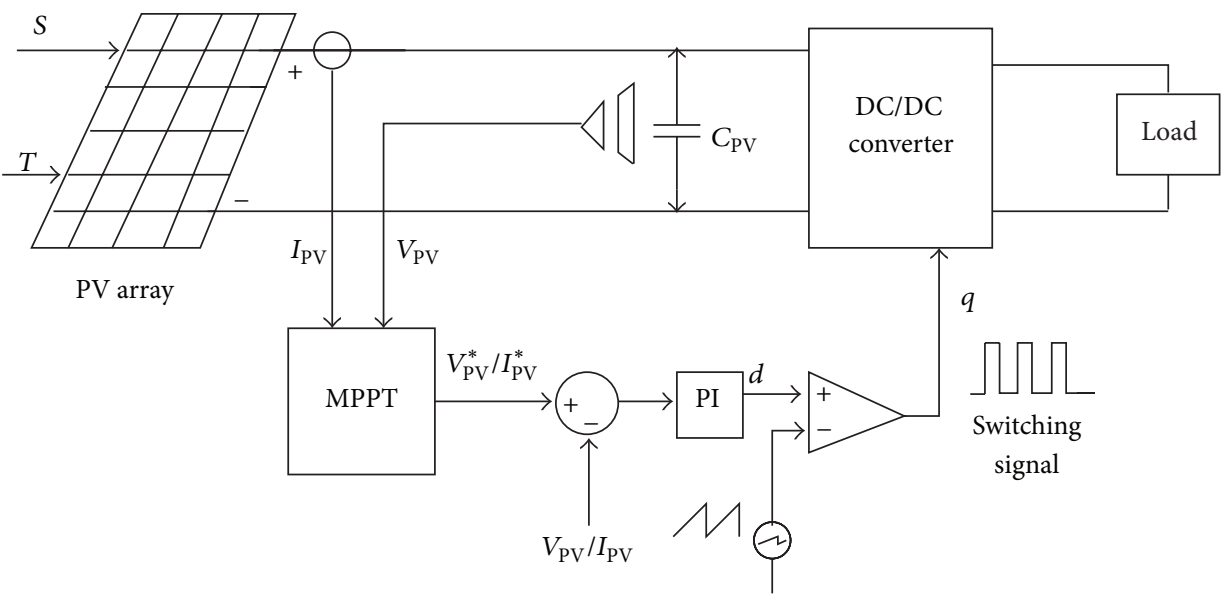

FIGURE 9: Main circuit structure based on proposed chaos search control. 

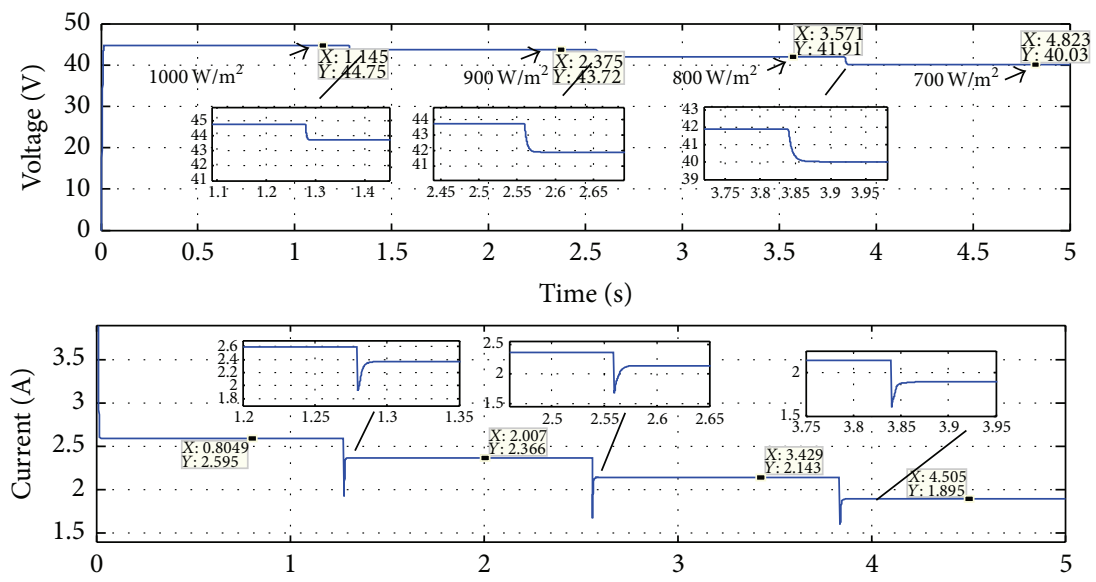

Time (s)

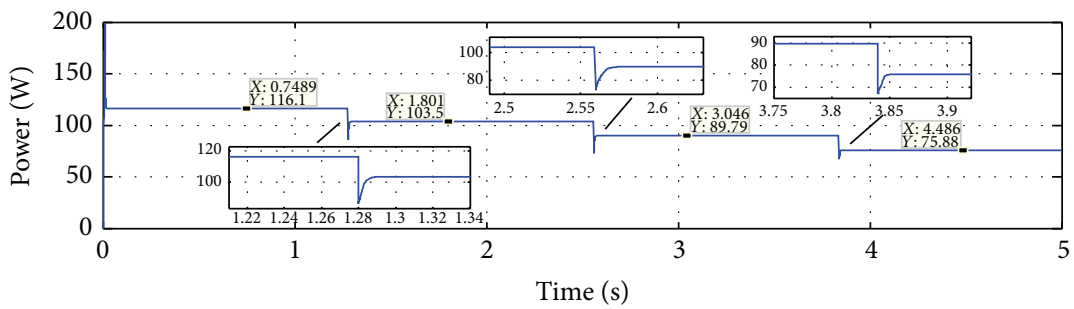

(a)
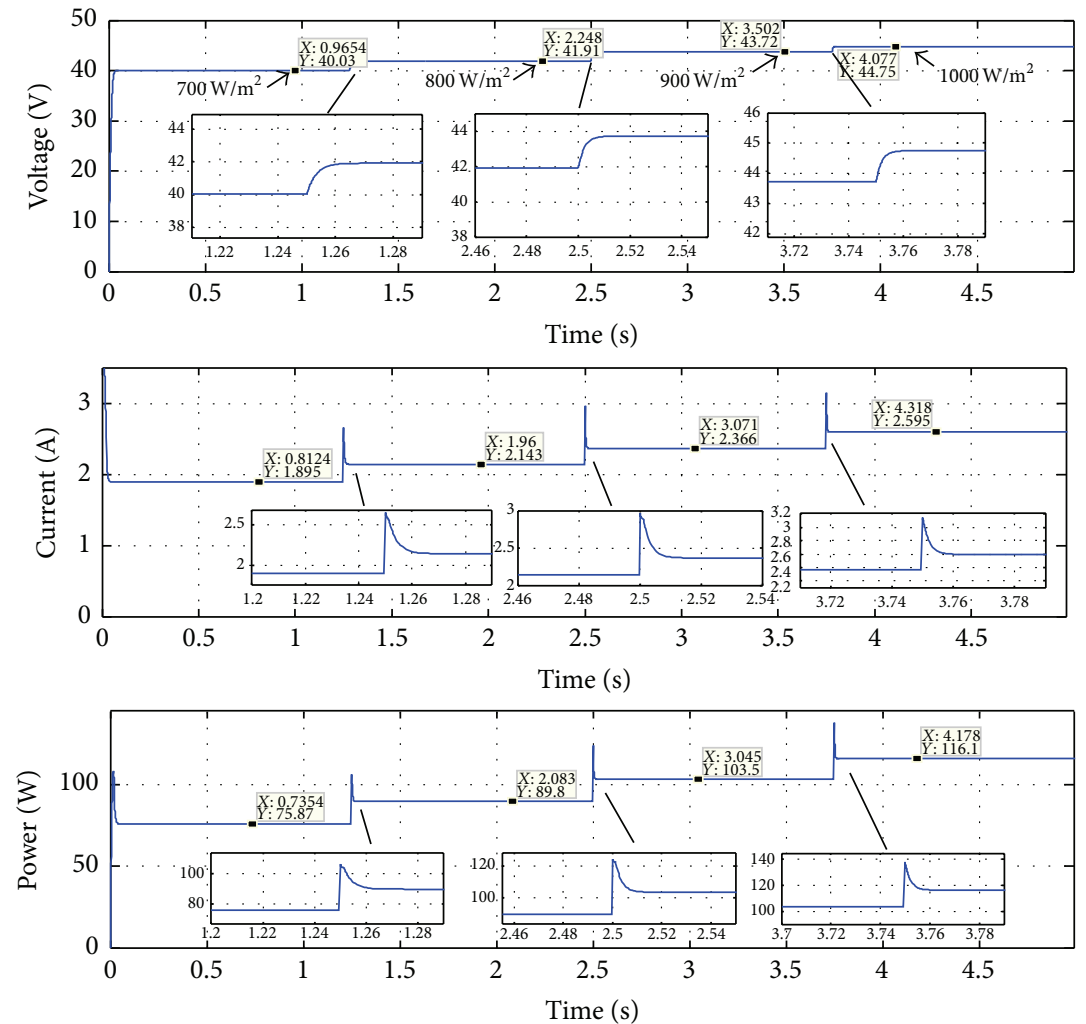

(b)

FIGURE 10: Simulation results of PV array under the rapid irradiation change. (a) Irradiation decrease. (b) Irradiation increase. 

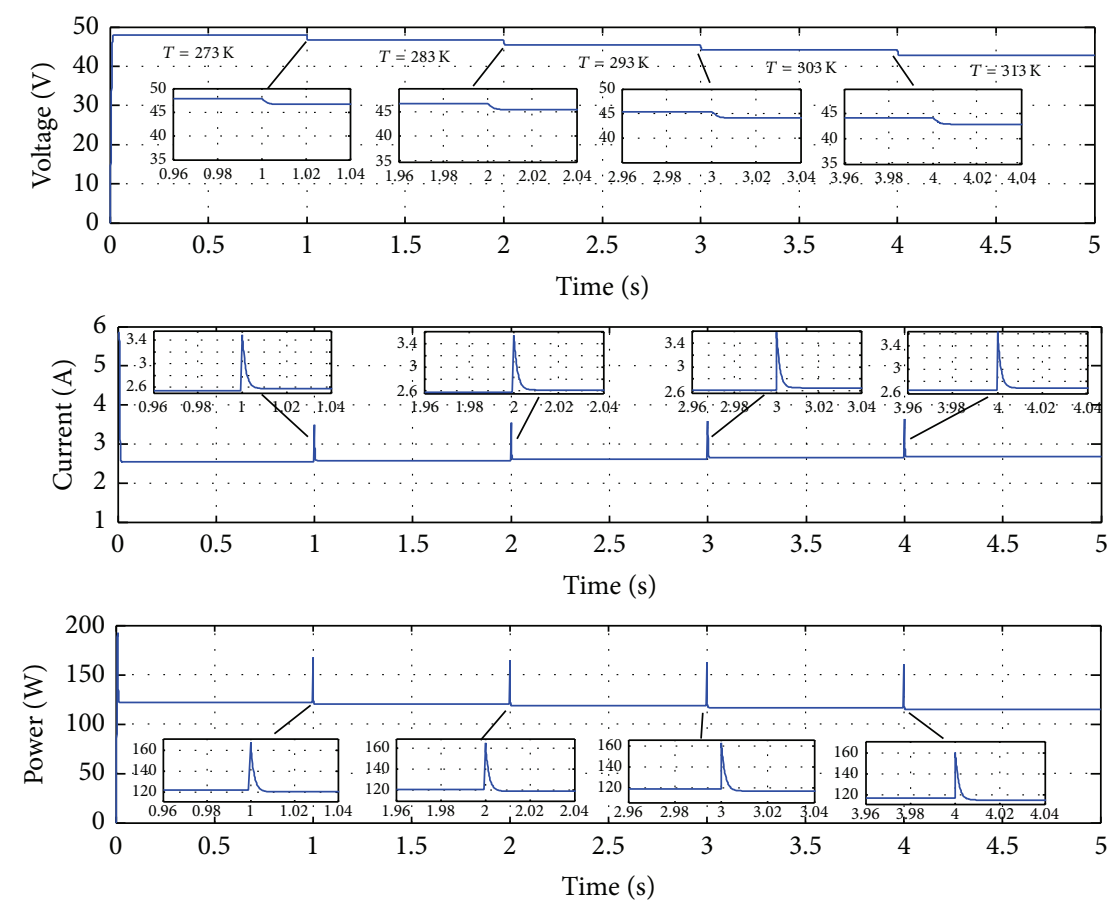

(a)
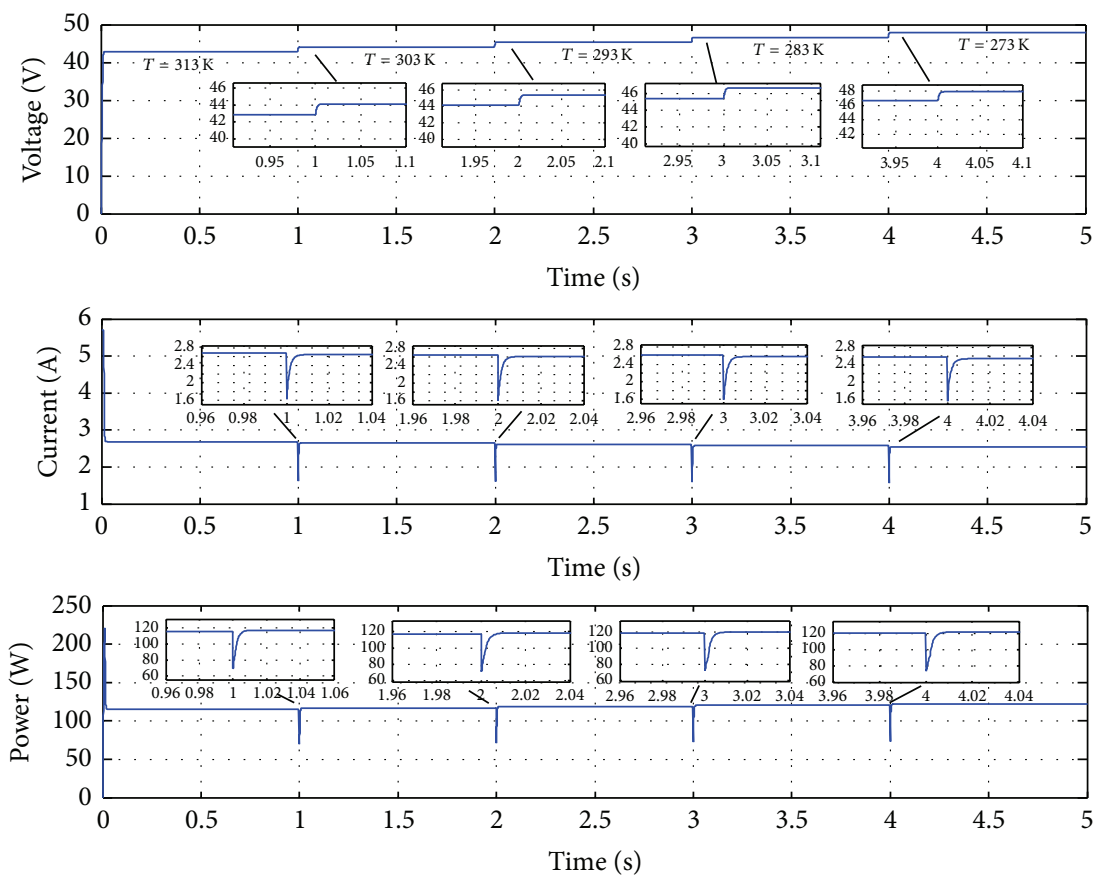

(b)

FIGURE 11: Simulation result of PV array under the rapid temperature change. (a) Temperature rise. (b) Temperature drop.

$\lambda_{I}=0.12 \% /{ }^{\circ} \mathrm{C}=0.003504 \mathrm{~A} /{ }^{\circ} \mathrm{C}$; open circuit voltage change of temperature $\lambda_{v}=-126.79 \mathrm{mV} /{ }^{\circ} \mathrm{C}$. The main circuit structure based on proposed two-stage chaos search control has been given in Figure 9.

\subsection{Simulation Results}

4.3.1. Simulation with Unimodal Power Output. Figure 10 shows the output performance of PV array using two-stage chaos search method under the irradiation step change conditions, while the circumstance temperature is $298 \mathrm{~K}$. Figure 10(a) shows the simulation with irradiation decrease: at the beginning, the irradiation is $1000 \mathrm{~W} / \mathrm{m}^{2}$, and the output of PV array is gradually controlled at $44.75 \mathrm{~V}$ and $2.595 \mathrm{~A}$, which is nearly steady at STC MPP $(44.90 \mathrm{~V}, 2.589 \mathrm{~A})$. Meanwhile, the output power of the PV array is about $116.13 \mathrm{~W}$, and the error is $0.103 \%$ (compared with the STC 

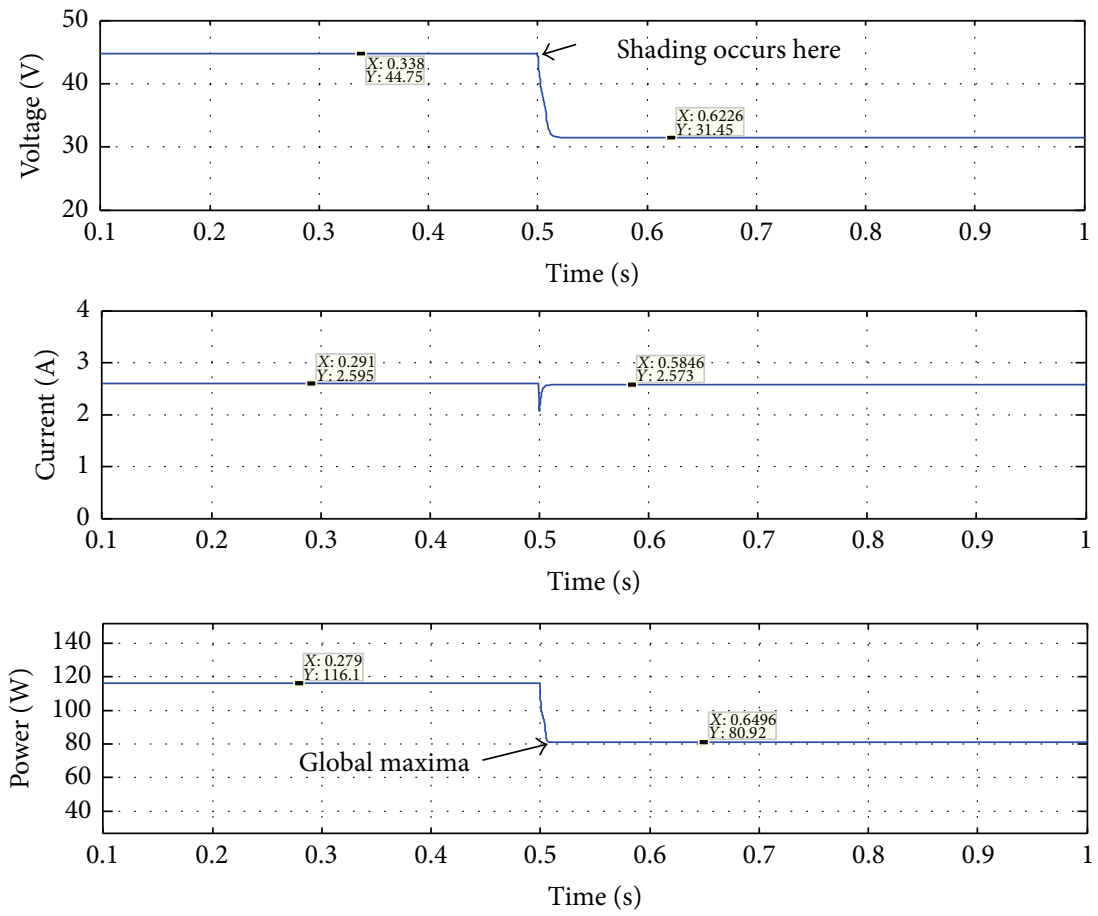

(a)
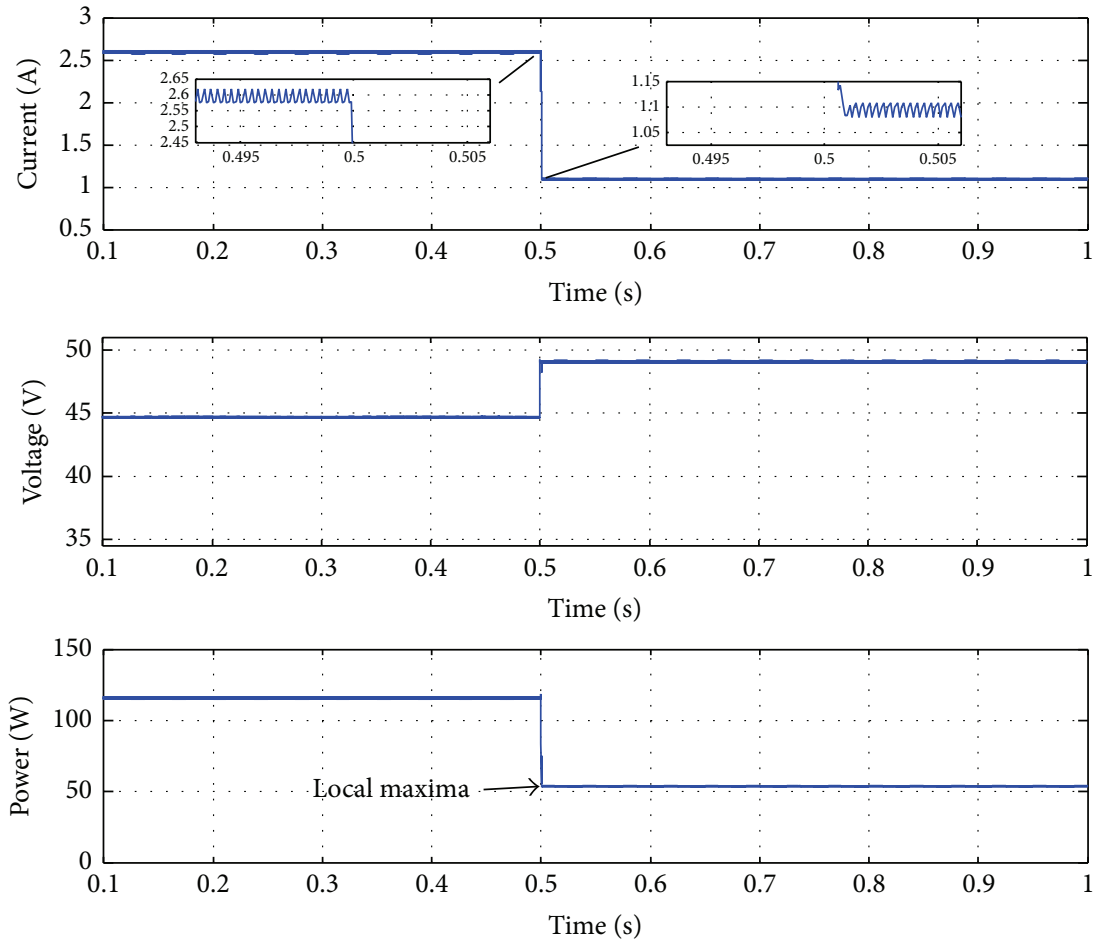

(b)

FIGURE 12: Simulation results of PV array under partial shading condition. (a) Two-stage chaos. (b) P\&O.

MPP $116.25 \mathrm{~W})$. At $t=1.28 \mathrm{~s}$, a step change is added to the irradiation from $1000 \mathrm{~W} / \mathrm{m}^{2}$ to $900 \mathrm{~W} / \mathrm{m}^{2}$, and then the output power of the PV array is quickly turning into $103.45 \mathrm{~W}$ $(43.72 \mathrm{~V}, 2.366 \mathrm{~A})$. At $t=2.56 \mathrm{~s}$, the irradiation is suddenly changing from $900 \mathrm{~W} / \mathrm{m}^{2}$ to $800 \mathrm{~W} / \mathrm{m}^{2}$, then the output power is promptly going down to $89.79 \mathrm{~W}(41.91 \mathrm{~V}, 2.143 \mathrm{~A})$. At $t=3.84 \mathrm{~s}$, the output power is changing from $800 \mathrm{~W} / \mathrm{m}^{2}$ to $700 \mathrm{~W} / \mathrm{m}^{2}$, the output power is rapidly dropping into 
75.88 W (40.03 V, 1.895 A). Figure 10(b) shows the simulation under the irradiation increase condition; the changing trend is opposite to Figure 10(a).

Figure 11 shows the output performance of PV array under the temperature step change conditions while the irradiation is $1000 \mathrm{~W} / \mathrm{m}^{2}$. In Figure 11(a), there is a temperature rising: a step change from $273 \mathrm{~K}$ to $283 \mathrm{~K}$ at $t=1 \mathrm{~s}$, from $283 \mathrm{~K}$ to $293 \mathrm{~K}$ at $t=2 \mathrm{~s}$, from $293 \mathrm{~K}$ to $303 \mathrm{~K}$ at $t=3 \mathrm{~s}$, and then continue to change from $303 \mathrm{~K}$ to $313 \mathrm{~K}$ at $t=$ $4 \mathrm{~s}$; in Figure 11(b), there is a temperature dropping, and the simulation shows that the tendency of output change of PV array is opposite to Figure 11(a).

From Figures 10 and 11, we can see that, while the circumstance conditions change, the voltage and current of PV array will respond quickly and overshoot less; the work state of PV system will be stabilized rapidly around the next MPP.

4.3.2. Simulation with Multimodal Power Output. To simulate the partial shading condition, the unshaded blocks (70 percent of the area) in the PV array are exposed to $1000 \mathrm{~W} / \mathrm{m}^{2}$ of solar irradiation, the shaded blocks (30 percent of the area) are exposed to $400 \mathrm{~W} / \mathrm{m}^{2}$ of solar insolation, and the circumstance temperature is $298 \mathrm{~K}$. Because of the natural behavior of the bypass diode which are connected inside the $\mathrm{PV}$ array, the $P_{\mathrm{PV}}-V_{\mathrm{PV}}$ curve of $\mathrm{PV}$ array under the partial shading condition must have two peaks: one is the global maximum power point (GMPP) and the other is the local maximum power point (LMPP). Under these conditions, traditional algorithms such as $\mathrm{P} \& \mathrm{O}$ method can only track either of the two MPPs; they cannot distinguish between them. If the LMPP was finally obtained, the output power of PV system will be significantly lower.

The simulation results are shown in Figure 12. Initially, the PV array receives a uniform irradiation of $1000 \mathrm{~W} / \mathrm{m}^{2}$. It is observed that until $t=0.5 \mathrm{~s}$, the output voltage and current are retained, respectively. At that time, in Figure 12(a), the operating point is stabilized at $44.75 \mathrm{~V}, 2.595 \mathrm{~A}$; in Figure 12(b), the operating point is stabilized around $44.69 \mathrm{~V}$, 2.598 A. At $t=0.5 \mathrm{~s}$, the shading occurs; in Figure 12(a), the operating point is shifted to a new MPP at 81.17 W (GMPP). While the new operating point of P\&O is shifted to LMPP $(53.51 \mathrm{~W})$, we can see that the tracking ability of the proposed method is superior than $\mathrm{P} \& \mathrm{O}$ method under the multimodal power output condition.

\section{Conclusion}

A novel two-stage chaos search method, which is first applied in the MPPT control for PV system has been proposed. In this method, an improved logistic mapping is used as the first carrier to produce chaos variables, and a power function carrier is used as the secondary carrier to reduce the search space. The proposed algorithm can overcome the blindness of the traditional chaos search and improve chaos search efficiency. The PV system simulation model has been built in MATLAB/Simulink with the mathematical model. Comparing the result of MPPT with the traditional single chaos and the $\mathrm{P} \& \mathrm{O}$ search, the proposed method has fast tracking response and superior performance. According to the PV system simulation under different circumstances, the error of maximum output power with the proposed method is about $0.103 \%$. The simulation shows that the proposed method is effective and valuable in MPPT.

\section{Conflict of Interests}

The authors declare that there is no conflict of interests regarding the publication of this paper.

\section{Acknowledgments}

This work was supported by the National Natural Science Foundation of China under Grant F011401 and by the Union Innovation Funds Project of Jiangsu Province China under Grant BY2013068.

\section{References}

[1] J. H. R. Enslin, "Maximum power point tracking: a cost saving necessity in solar energy systems," Renewable Energy, vol. 2, no. 6, pp. 543-549, 1992.

[2] V. Salas, E. Olías, A. Barrado, and A. Lázaro, "Review of the maximum power point tracking algorithms for stand-alone photovoltaic systems," Solar Energy Materials and Solar Cells, vol. 90, no. 11, pp. 1555-1578, 2006.

[3] V. Badescu, "Simple optimization procedure for silicon-based solar cell interconnection in a series-parallel PV module," Energy Conversion and Management, vol. 47, no. 9-10, pp. 11461158, 2006.

[4] B. D. Clegg, Photovoltaic principles and design of a maximum power point tracker [M.S. thesis], Kansas State University, Manhattan, Kan, USA, 1996.

[5] T. Tafticht, K. Agbossou, M. L. Doumbia, and A. Chériti, "An improved maximum power point tracking method for photovoltaic systems," Renewable Energy, vol. 33, no. 7, pp. 15081516, 2008.

[6] F. Liu, Y. Kang, Y. Zhang, and S. Duan, "Comparison of $\mathrm{P} \& \mathrm{O}$ and hill climbing MPPT methods for grid-connected PV converter," in Proceedings of the 3rd IEEE Conference on Industrial Electronics and Applications (ICIEA '08), pp. 804-807, Singapore, June 2008.

[7] Z. Yan, L. Fei, and Y. Jinjun, "Study on realizing MPPT by improved incremental conductance method with variable stepsize," in Proceedings of the $3 r$ IEEE Conference on Industrial Electronics and Applications, pp. 547-550, 2008.

[8] J. Li and H. Wang, "Maximum power point tracking of photovoltaic generation based on the optimal gradient method," in Proceedings of the Asia-Pacific Power and Energy Engineering Conference, pp. 692-695, 2009.

[9] S.-Y. Yang, L.-H. Wu, and Z.-X. Liu, "Research on photovoltaic grid-connected generation system," in Proceedings of the International Conference on Manufacturing Science and Technology, pp. 383-390, 2011.

[10] A. I. Dounis, P. Kofinas, C. Alafodimos, and D. Tseles, "Adaptive fuzzy gain scheduling PID controller for maximum power point tracking of photovoltaic system," Renewable Energy, vol. 60, pp. 202-214, 2013. 
[11] C.-S. Chiu, Z.-H. Li, and Y.-H. Chen, "T-S fuzzy direct maximum power point tracking of wind energy conversion systems," International Journal of Fuzzy Systems, vol. 15, no. 2, pp. 192-202, 2013.

[12] A. Al Nabulsi and R. Dhaouadi, "Efficiency optimization of a dsp-based standalone PV system using fuzzy logic and dualMPPT control," IEEE Transactions on Industrial Informatics, vol. 8, no. 3, pp. 573-584, 2012.

[13] M. Adly and A. H. Besheer, "A meta-heuristics search algorithm as a solution for energy transfer maximization in stand-alone photovoltaic systems," International Journal of Electrical Power \& Energy Systems, vol. 51, pp. 243-254, 2013.

[14] K. Ishaque and Z. Salam, "A review of maximum power point tracking techniques of PV system for uniform insolation and partial shading condition," Renewable and Sustainable Energy Reviews, vol. 19, pp. 475-488, 2013.

[15] J. W. Bishop, "Computer simulation of the effects of electrical mismatches in photovoltaic cell interconnection circuits," Solar Cells, vol. 25, no. 1, pp. 73-89, 1988.

[16] R. Kadri, H. Andrei, J.-P. Gaubert, T. Ivanovici, G. Champenois, and P. Andrei, "Modeling of the photovoltaic cell circuit parameters for optimum connection model and real-time emulator with partial shadow conditions," Energy, vol. 42, no. 1, pp. 5767,2012

[17] J. A. Gow and C. D. Manning, "Development of a photovoltaic array model for use in power-electronics simulation studies," IEE Proceedings: Electric Power Applications, vol. 146, no. 2, pp. 193-200, 1999.

[18] M. K. El-Adawi and I. A. Al-Nuaim, "A method to determine the solar cell series resistance from a single I-V. Characteristic curve considering its shunt resistance-new approach," Vacuum, vol. 64, no. 1, pp. 33-36, 2001.

[19] D. Yang, G. Li, and G. Cheng, "On the efficiency of chaos optimization algorithms for global optimization," Chaos, Solitons and Fractals, vol. 34, no. 4, pp. 1366-1375, 2007.

[20] L. Li, Y. Yang, H. Peng, and X. Wang, "An optimization method inspired by "chaotic" ant behavior," International Journal of Bifurcation and Chaos, vol. 16, no. 8, pp. 2351-2364, 2006.

[21] O. Hugues-Salas and S. P. Banks, "Optimal control of chaos in nonlinear driven oscillators via linear time-varying approximations," International Journal of Bifurcation and Chaos in Applied Sciences and Engineering, vol. 18, no. 11, pp. 3355-3374, 2008.

[22] V. Piccirillo, J. M. Balthazar, B. R. Pontes Jr., and J. L. P. Felix, "Chaos control of a nonlinear oscillator with shape memory alloy using an optimal linear control: part II: nonideal energy source," Nonlinear Dynamics, vol. 56, no. 3, pp. 243-253, 2009.

[23] P. Wang, D. Li, X. Wu, J. Lü, and X. Yu, "Ultimate bound estimation of a class of high dimensional quadratic autonomous dynamical systems," International Journal of Bifurcation and Chaos in Applied Sciences and Engineering, vol. 21, no. 9, pp. 2679-2694, 2011.

[24] L. Zhou, Y. Chen, K. Guo, and F. Jia, "New approach for MPPT control of photovoltaic system with mutative-scale dual-carrier chaotic search," IEEE Transactions on Power Electronics, vol. 26, no. 4, pp. 1038-1048, 2011.

[25] W. Seifritz, "Functional logistic mapping," Chaos, Solitons and Fractals, vol. 7, no. 9, pp. 1417-1425, 1996.

[26] Z. Lin, C. Yan, L. Qiang, and W. Jian, "Maximum power point tracking (MPPT) control of a photovoltaic system based on dual carrier chaotic search," Journal of Control Theory and Applications, vol. 10, no. 2, pp. 244-250, 2012.
[27] Y.-C. Wu, M.-J. Chen, S.-H. Huang, M.-T. Tsai, and C.-H. $\mathrm{Li}$, "Maximum power point tracking on stand-alone solar power system: three-point-weighting method incorporating mid-point tracking," International Journal of Electrical Power and Energy Systems, vol. 52, no. 1, pp. 14-24, 2013. 


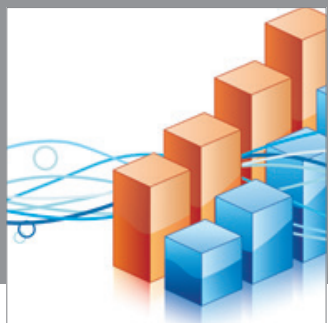

Advances in

Operations Research

mansans

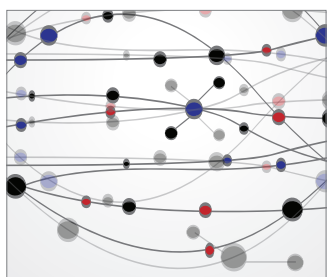

The Scientific World Journal
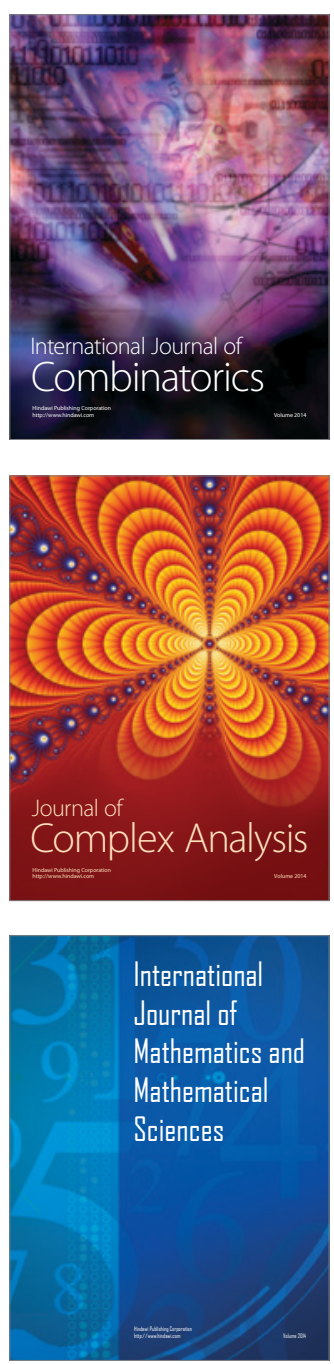
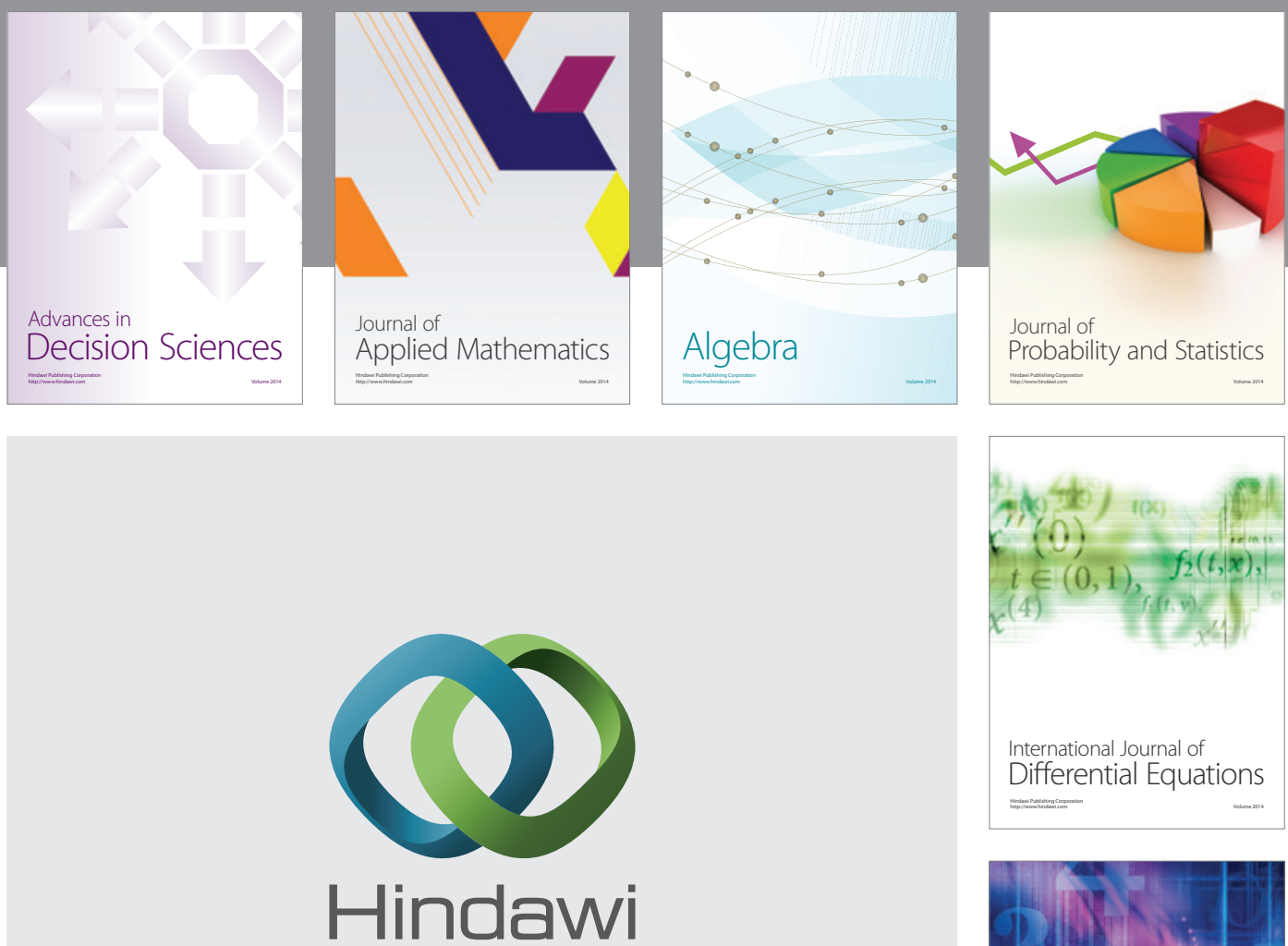

Submit your manuscripts at http://www.hindawi.com
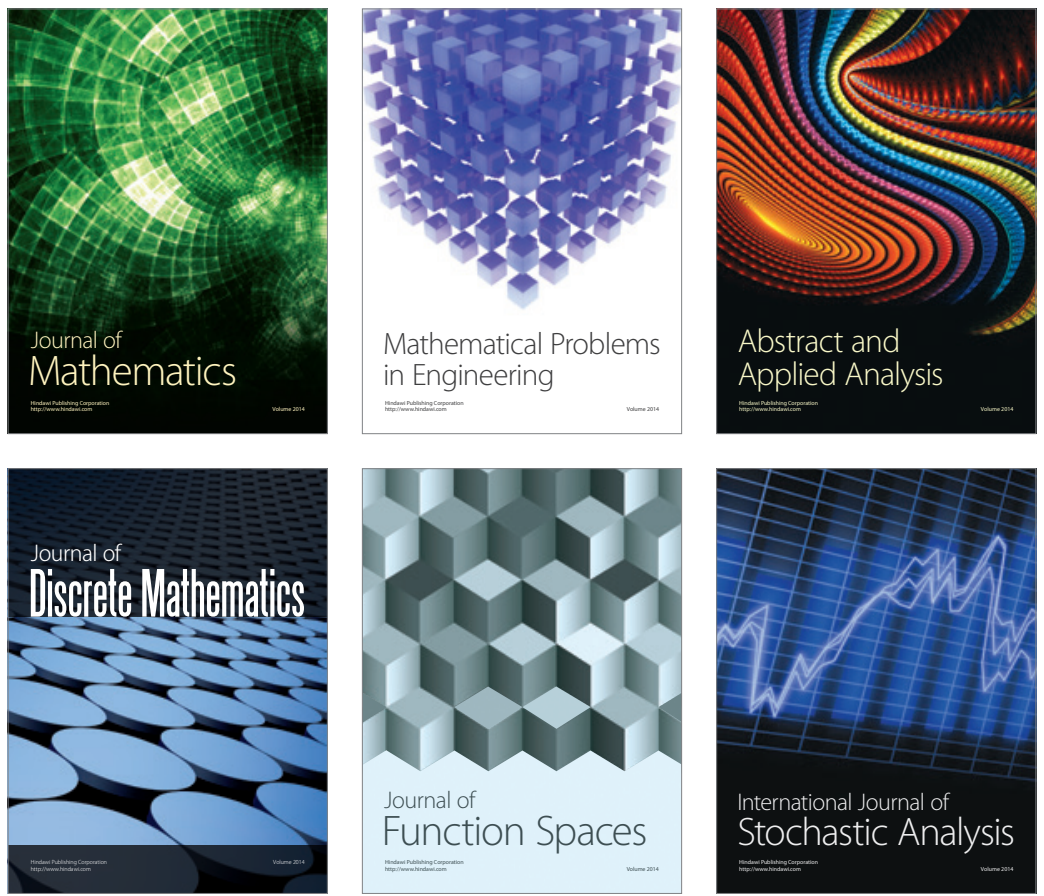

Journal of

Function Spaces

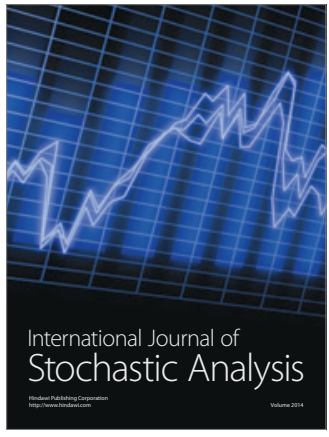

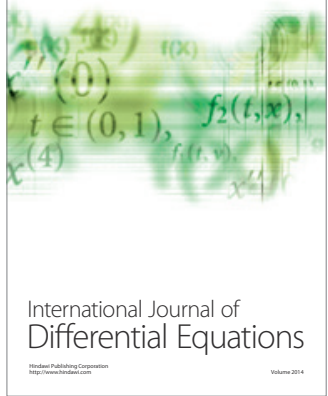
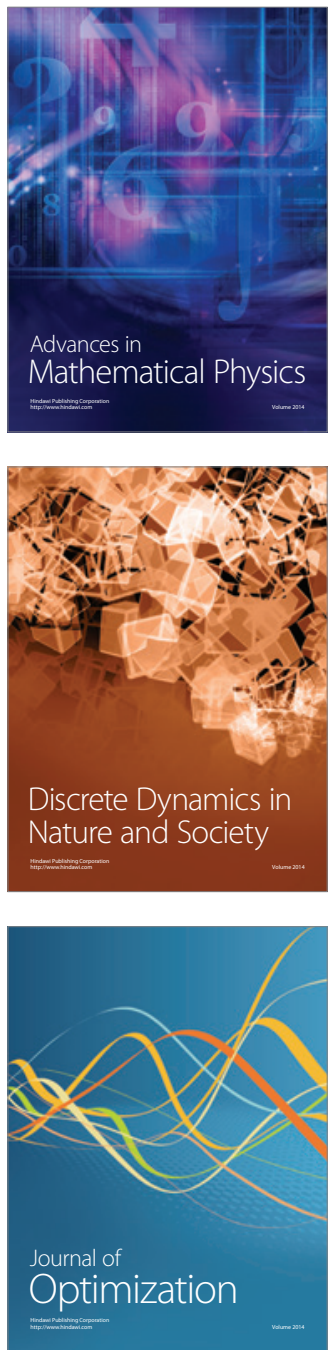